\title{
Pricing A Pig In A Poke: Endogenous Valuations And Storage Unit Auctions
}

Craig H. Wisen, University of Alaska Fairbanks, USA

Kevin C. H. Chiang, University of Vermont, USA

Michael P. Pippenger, University of Alaska Fairbanks, USA

James M. Collins, University of Alaska Fairbanks, USA

\begin{abstract}
Storage unit auctions have recently received widespread attention from reality shows and "get rich easy" business models. This study examines the pitfalls associated with winning storage unit auctions, commonly observed bidding strategies, participant behavior and auction methods. Storage unit auctions present a classic example of endogenous valuation using incomplete information and imperfect secondary markets. The examination of the contents of a storage unit auction yields a novel use for the facility and sheds light on the process that leads to a lien and sale.
\end{abstract}

Keywords: Endogenous Valuation; Storage Unit Auction; Reality TV

\section{INTRODUCTION}

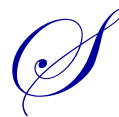

torage unit auctions have received widespread attention due to the Storage Wars reality TV show produced by the A\&E network. From its home page, the description of the show is as follows: "Storage Wars, which follows teams of bidders looking to score it big in the high stakes world of storage auctions... ranked as A\&E's number one series ... and the number three nonfiction show on cable among adults aged 25-54." The series' second season averaged 4.7 million total viewers and, in November 2011, hit an all-time high of 5.6 million viewers, making it the series' most-watched episode and the network's \#1 original series telecast of all time" (http://www.aetv.com/storage-wars/about/).

A natural bias is imparted on viewers of Storage Wars due to editing and A\&E profit motives. A similar bias is created by authors of "get rich quick" books that purport to show readers how they can profit from garage sales and storage unit auctions. The present study seeks to impart a better understanding of the process that leads to liens being placed on storage units, the behavior of auction participants, and the challenges of valuation.

\section{Auction Mechanics}

Storage units are frequently auctioned off throughout the country and a cottage industry of data aggregators has taken notice. A partial list includes websites such as auctionmoneygenerator.com, storageunitauctionlist.com, taxlienlady.com, txssa.org, auctionstx.com, storagebattles.com, storageauctionskings.com, and fasttrackauction.com.

State law usually prescribes the notification requirements prior to auctioning off storage units due to nonpayment of storage fees within the United States. The current study took place at the Interior Mini Storage facility in Fairbanks, Alaska, on November 30, 2012. The studied auction is a first-price, sealed-bid auction. ${ }^{1}$ Announcements of the auction were published in the local newspaper several times in the weeks leading up to the event and previews were scheduled for the afternoon of the auction and two days prior to the auction. The announcement included the names of the individuals who leased the storage units and the storage units' numbers. Leasees had until the day of the auction to pay their bills in full in order to prevent the contents of the unit from

\footnotetext{
${ }^{1}$ See Klemperer (1999) for a theoretical and empirical review of the auction literature.
} 
being auctioned off. Fifteen of the 18 units listed in the auction announcement paid their bills prior to auction time and the remaining three units were auctioned off at 6 p.m. For each auction, the highest sealed bid won the auction. Winning the auction came with an obligation to clear the contents out within three days.

Previewing the contents of a storage unit is challenging due to dim lighting, obstructions, and opaque packing. The duration of the preview for each unit typically lasted 3-5 minutes, and activities displayed included the use of flashlights and digital photography or video recording of visible contents. Previewers were not allowed inside the units; therefore, some individuals would hold their recording equipment as high as possible to gain a better view of boxed contents.

Storage unit sales differ from other auction-based transactions. For instance, in traditional - including most online - auctions, the item offered for sale is identified and described in some detail. In addition to that, prospective buyers have the opportunity to carefully inspect the item, in person in the case of most auctions, and photographically in online environments. Questions about the provenance or condition of the item can also be asked and answered. The information obtained via descriptions and close inspection aids buyers in the process of forming expectations of the value of the item offered before bidding. In essence, the outcome space is well articulated. While bidders may well form different estimates of the expected value of the various outcomes, there is little disagreement about the outcome space itself.

Although the storage unit sale process includes a rudimentary preview, or inspection, opportunity, the principle lure of these auctions is what cannot be known. The prospective buyer must not only assign expectations to states, but he must, in large measure, conjure up what those states are. The contents of a large, sealed cardboard box might contain dirty laundry, currency, or an unknown Rembrandt. Information theory, and by extension, statistical analysis, assess uncertainty under the assumption that the outcome space is known or can be described in terms of distributions. The central problem facing bidders in storage unit auctions is not assessing value based on what is known, but the puzzle of dealing with the unknowable. ${ }^{2}$

Of course, from the point of view of a rational investor, the risk associated with a traditional auction transaction, whether it is for wine, antiques, or firearms, is concerned with how markets might evaluate the item after the auction. The risk associated with storage unit auctions is much different: "What is being offered?" is the issue being faced. As in the popular TV shows, bidders in the latter case can only rely on imprecise assessments of the fuzzy notion of "treasure." To some degree, winning a treasure is like winning a lottery; that is, the best outcome is at the far right of the return distribution. Nevertheless, the left tail of return distribution for participating in storage unit auctions is very different from that of a lottery. ${ }^{3}$ A lottery has a well-defined, limited liability; that is, the most one can lose is the dollar amount wagered. In contrast, winning a storage unit involves an obligation to clear the unit. This obligation has unlimited liability in the sense that the potential cost of clearing the unit may be extremely high when it contains biological waste, chemical waste, and other hazardous items.

The idiom a pig in the poke is an English colloquialism that dates back to the Middle Ages and refers to the problem of buying meat of unknown origins without an opportunity for inspection because it is held in a poke, bag, or pocket. Alternative expressions in other languages refer to the purchase of cats, dogs, or piglets in a bag. "Caveat Emptor", Latin for buyer beware, is one principle of commerce - that it is the buyer's responsibility to accept the risk that their perceptions prior to purchase might be inaccurate. The idiom let the cat out of the bag is related to $a$ pig in a poke. Cats were deemed to be less valuable than pigs in Medieval times because cats were more numerous and the meat did not taste as good as pigs. Letting the cat out of the bag reflects the recognition that a seller attempted to cheat a buyer by substituting a lower value animal.

Storage Wars segments often present the opposite of a pig in the poke. It focuses on the rare occurrence where the contents of the storage unit hold a hidden treasure. In reference to this, $\mathrm{ABC}$ published the following on their website: "A San Jose man needed no treasure map when he reportedly stumbled onto $\$ 500,000$ worth of gold and silver after bidding on an abandoned storage unit. The man, identified only as John, apparently paid $\$ 1,100$ for

\footnotetext{
${ }^{2}$ That is, bidders face Knightian Uncertainty (Knight, 1921).

${ }^{3}$ The pricing of a lottery can be understood as the pricing of nonsystematic risk (Green and Rydqvist, 1997).
} 
the unit only to see his blind investment turn into a goldmine after a number of rare coins and a few gold and silver bars were found in the blue Rubbermaid container" (http://abcnews.go.com/US/man-reported-find-500000-worthtreasure-storage-unit/story?id=14958206).

Potential bidders often envision an auction outcome based on the idealized presence of "treasure". The goal then becomes the determination of a loosely defined probability that items of value lie hidden in the contents of the storage unit. Glendon Cameron, in his entertaining book The Porn is Always in the DVD Player-My Life as a Storage Auction Addict, describes an imprecise, highly subjective strategy to assess the value of the units' contents.

The authors describe a bidding strategy that seeks to clarify the assignment function of whether or not a particular unit contains "treasure."

Factors causing treasures to be absent are:

- If the lessee knows in advance that they will be unable or unwilling to pay the storage unit rental bill, then they can access the unit prior to the auction and remove the most valuable contents.

- $\quad$ The lessee is unlikely to have treasure and an inability to pay a storage unit bill.

- Insiders and owners of the storage facility might inspect the contents prior to the auction and remove the most valuable items.

Factors causing treasures to be present are:

- $\quad$ The lessee is uncertain of the storage unit contents or value.

- $\quad$ The lessee is dead, in rehabilitation, incarcerated, or otherwise incapacitated.

The State of Alaska has an easily accessible database of criminal convictions (http://www.courtrecords.alaska.gov/eservices/home.page.3).

Customer storage unit names were input into the Alaska court record database prior to attending the auction. Two individuals leased the unit purchased at the auction. The first individual had two records - driving without a valid license and Class A misdemeanors related to domestic violence, intimidation, and weapons. The first lessee was not in prison at the time of the auction and the second lessee had no criminal convictions or criminal charges.

The winning bid for the storage unit in this study was $\$ 65$. Winning the auction came with an obligation to clear the contents out within three days. Auction participants are essentially bidding on an opaque balance sheet composed of assets and liabilities. There is a possibility that one might pay for a storage unit whose content liability exceeds the content assets. From a financial perspective, this is termed negative equity. With perfect information in this hypothetical case, bidders would have to be paid to "win" the auction instead of paying money to the storage facility.

Fairbanks, Alaska, uses dumpsites called "transfer stations" which, at present, do not charge a user fee. Disposal of liabilities or contents whose value would be exceeded by selling costs, were taken to the transfer station. Expenses were related primarily to fuel and labor.

Items that were retained consisted of the following:

- $\quad$ Can of Alaskan salmon

- $\quad$ Unused box of extra-large Tough Strips Band-Aids

- $\quad$ Nikon CoolPix digital camera

- $\quad$ Can opener

- $\quad$ Baseball cap

- $\quad$ Kitchen knife 
The remaining storage unit contents consisted of the following:

- $\quad$ Lazy-Boy chair in poor condition
- $\quad$ Esed stereo equipment
- $\quad$ Used condoms
- $\quad$ Soiled and new articles of clothing
- $\quad$ A device used to smoke unknown substances
- $\quad$ Sitchen items
- $\quad$ Personal effects such as grooming devices and DVDs

Using a storage facility to store empty liquor bottles and used condoms was perplexing; however, given the positioning of and stains on the Lazy Boy, a natural hypothesis was that the storage unit was being used as a makeshift brothel.

After spending the better part of the day with a temperature of $-40 \mathrm{~F}$ shuttling items to the transfer station, the authors would not have bid $\$ 65$ for the contents of the storage unit. Considering the value of the items retained, and the time and expense associated with disposing of the remaining storage unit contents, the net value was approximately negative $\$ 100$. With perfect information, the winning bidder should have been paid $\$ 100$ to clear out the storage unit. It is interesting that after depositing items at the transfer station, the authors noted that individuals, colloquially known as "dumpster divers", inspected some of the items, although none appeared to have been taken.

\section{SUMMARY}

This study examined the negative outcomes associated with winning a storage unit auction and outlined commonly observed bidding strategies, participant behavior, and auction methods. This auction presented a classic example of endogenous valuation using incomplete information and imperfect secondary markets. A complete examination of one's auctioned unit contents presented a novel use for the storage facility and factors that lead to a lien and sale.

\section{AUTHOR INFORMATION}

Craig H. Wisen is an Associate Professor at the University of Alaska Fairbanks, School of Management, 303 Tanana Dr. Fairbanks, Alaska 99775. Corresponding author. Email: chwisen@alaska.edu.

Michael Pippenger is an Associate Professor at the University of Alaska Fairbanks, School of Management, 303 Tanana Dr. Fairbanks, Alaska 99775. Email: mkpippenger@alaska.edu.

James M. Collins is an Associate Professor at the University of Alaska Fairbanks, School of Management, 303 Tanana Dr. Fairbanks, Alaska 99775. Email: jmcollins@alaska.edu.

Kevin C. H. Chiang is a Professor of Real Estate/Finance at the University of Vermont School Of Business. Email: kcchiang@bsad.uvm.edu.

\section{REFERENCES}

1. Green, R. C. \& Rydqvist, K. (1997). The valuation of nonsystematic risk and the pricing of Swedish lottery bonds. Review of Financial Studies, 10(2), 447-480.

2. Klemperer, P. (1999). Auction theory: A guide to the literature. Journal of Economic Surveys, 13(3), 227286. 